\title{
Fear of crime and preference for aggressive-formidable same-sex and opposite-sex friends
}

\author{
Justina Meskelyte ${ }^{1} \cdot$ Minna Lyons $^{1}$ \\ Published online: 3 March 2020 \\ (C) The Author(s) 2020
}

\begin{abstract}
Previous research has found that when faced with dangerous environments, women may have an evolved preference for physically strong and aggressive men. This phenomenon has been named as the Bodyguard hypothesis. The aim of the present studies was to explore whether the same principle exists in non-romantic male friend selection. In Study 1, $(n=118)$, an on-line sample of British women was assessed for objective crime rates in their childhood and current environment, subjective vulnerability to crime, and preference for aggressive and formidable opposite-sex friends. Women's subjective fear of crime predicted their preference for aggressive-formidable ideal male friends, as well as aggressive-formidable actual male friends. In Study 2 $(n=228)$, an internet sample of both sexes was assessed for their subjective fear of crime, as well as their preference for aggressive-formidability and other characteristics in same and opposite-sex friends. Fear of crime was not correlated with characteristics (intelligence, funniness, kindness) that were unrelated to aggressive-formidability. There was a small positive correlation between fear of crime and preference for aggressive-formidable friends in both sexes. The correlation between fear of crime and preference for ideal male friend's aggression-formidability was the only statistically significant one, and none of the correlations differed significantly from each other. Together, these two studies provide some tentative evidence for the Bodyguard hypothesis in preferred friendship characteristics. Environmental influence on friendship selection is an under-investigated area of research, benefiting from future research replicating the methodology from studies on romantic partner characteristics.
\end{abstract}

Keywords Opposite-sex friendships, bodyguard hypothesis $\cdot$ Objective childhood crime rates $\cdot$ Objective current crime rates $\cdot$ Fear of crime

\section{Introduction}

Opposite-sex friendships (OSF's) may be defined as a "voluntary, cooperative, non-romantic alliance between members of the opposite sex" (Bleske-Rechek et al. 2012, p.570). Although they are relatively common in humans (Monsour 2002) and in non-human primates (e.g., baboons; Goffe et al. 2016), the motives for pursuing OSFs have not been extensively researched. Interestingly, one study found that the characteristics that people prefer in the OSFs are more similar to those that they seek for in non-platonic relationships than in same-sex friendships (Sprecher and Regan 2002). According to evolutionary perspective, a close bond with an opposite-sex individual could benefit men by providing them

Minna Lyons

m.lyons@liv.ac.uk

1 School of Psychology, The University of Liverpool, Bedford Street South, Liverpool L69 7ZA, UK sexual access to a female friend (Bleske-Rechek and Buss 2001). On the other hand, women may expect the benefit of physical protection from violence (the "Bodyguard hypothesis"; Bleske-Rechek and Buss 2001; Wilson and Mesnick 1997) or from other environmental threats (the "Environmental security hypothesis"; Reeve et al. 2019). In this study, our aim is to investigate the Bodyguard hypothesis in relation to women's choice for opposite-sex friend characteristics that could be beneficial in providing protection.

According to the Bodyguard hypothesis, women may have an evolved preference for mates and male friends who are able to protect them from aggression from other men (Bleske-Rechek and Buss 2001; Buss and Schmitt 1993; Wilson and Mesnick 1997). Thus, women, more than men, should prefer OSFs that have characteristics indicative of better ability to offer protection (i.e., physical strength, aggressive and dominant personality traits; Bleske-Rechek and Buss 2001). However, associating with formidable men has apparent costs too, as women and their offspring are vulnerable to aggression from the "protector" (see, for example, Borras-Guevara et al. 2017). We would expect, then, that women's preference for aggressive-formidable male 
friends depends on the level of external risk in the environment of the woman. In theory, women who live in dangerous areas should have a stronger preference for physical strength in opposite-sex friends (Bleske-Rechek and Buss 2001), because the benefits of the protection may outweigh the costs of aggression. However, the current literature has focussed on investigating women's preference for romantic partners rather than nonromantic, platonic friends.

Previous research suggests that especially in dangerous neighbourhoods (Snyder et al. 2011), and under other environmental threats (Reeve et al. 2016), women prefer physically strong and/or dominant males as romantic partners. Interestingly, when investigating preference for formidable romantic partners, research has found that subjective fear of crime is a stronger predictor than the objective risk of crime (Snyder et al. 2011; Ryder et al. 2016). Fear of crime, in turn, is influenced by exposure to violent crime in childhood (Snyder et al. 2011), as well as crime in the current neighbourhood environment (Zhao et al. 2015). If platonic male friends are chosen because they provide protection, women who have elevated subjective fear of crime should prefer more aggressive and formidable men as their non-romantic friends.

In the present studies, we aim to add to the scarce literature on environmental influences on friendship selection by partially replicating the method used by Snyder et al. (2011), who studied the Bodyguard hypothesis in romantic partner preference. Based on previous literature on mate choice, we expect that both childhood and current neighbourhood objective crime rate relates not only to women's preference for male friends who are aggressive and formidable, but also to higher manifestation of these traits in their actual male friends. Similarly, we expect that subjective fear of crime is positively associated with women's choice of aggressive-formidable male friends, perhaps even more so than objective crime (see Snyder et al. 2011; Ryder et al. 2016 for similar findings in romantic partner preferences). In addition, we expect that fear of crime is unrelated to friend characteristics that are irrelevant in providing physical protection. Finally, we predict that any correlations between fear of crime and aggressive-formidability in actual and ideal friends will be stronger for women than for men, and within women, stronger for opposite, rather than same-sex friends.

\section{Method Study 1}

\section{Participants}

This online study had a final sample of 118 British females between the ages of $18-26$ (mean $=19.91, \mathrm{SD}=1.73$ ). Participants were recruited via voluntary, opportunity sampling, advertised via the researchers social media, and via an online psychology participation scheme in exchange of course credits.

\section{Materials}

In order to measure participant's exposure to crime in childhood, we asked what the postal code was in their childhood home that they lived the longest in. In order to get an index for the current crime rates, we also asked what the postal code of their current neighbourhood was. We used the English Indices of Deprivation (2015) Index of Multiple Deprivation calculator to get the average crime rate (ranging from $0=$ high crime rate, to $10=$ low crime rate) for the reported postal codes. The postcode data also provides a proxy for Socio-Economic Status (SES; i.e., high crime rate indicates low SES). Although the crime rate data were based on the information of the postal code in year 2015, neighbourhoods in England are slow to change (Tunstall 2016). Thus, we can expect that for our sample of 18-25 year olds, the crime information from 2015 is a fairly accurate reflection of both their current, and their childhood postal code crime rates.

The subjective fear of crime was measured using the modified version of The British Fear of Local Crime Survey, which was altered and used by Snyder et al. (2011). The original version could be accessed at the Office for National Statistics (2017). The scale of 1-4 from 'not at all worried' to 'very worried' assessed the participants' individual perception towards their vulnerability of being a victim of mugging, violent attack, sexual assault, burglary, vehicle damage/vandalism, theft from one's property, motor vehicle theft and general vandalism. These eight items were summed together to form an index of participants' current fear of crime.

The Dominance Trait Scale (Snyder et al. 2011; Poore et al. 2006), assessed women's preferences for aggressiveformidable male friends. The scale consisted of various traits related to attributes of aggressive forms of dominance, nonaggressive forms of status and physical characteristics. The eleven items included characteristics such as 'dominant', 'commanding', 'broad shoulders', 'could win a fight if necessary'. Women's preferences for those traits were recorded on a scale of $1-10(1=$ Not at all important, $10=$ Extremely important). We asked the participants to fill in the scale twice- first with regard to importance of the traits in an ideal male friend, and after that, with regard to the characteristics of their actual closest male friend. In order to prompt the participants to think about their actual male friend, we asked them to write down the initials of the male friends that they were thinking about. The items were summed together to form an index of aggressiveness-formidability in an ideal male friend, and in an actual male friend.

\section{Results and Discussion Study 1}

To test the hypotheses that childhood and current neighbourhood crime rates and fear of crime are related to 
preference for aggressive-formidable ideal and actual male friends, we carried out bivariate Pearson's correlations. As shown in Table 1, there was a significant positive relationship between aggressive-formidability preference in an ideal male friend and actual aggressive-formidability of the closest male friend. Fear of crime was significantly correlated with higher aggressive-formidability ratings of an ideal friend and an actual male friend. There were no significant correlations between current and childhood crime rates, and aggressiveness-formidability in ideal and actual male friends (see Table 1 for correlations and descriptive statistics).

In order to investigate the relative contribution of objective and subjective measures of crime, we conducted two multiple linear regressions with either ideal, or actual aggressiveformidable male friend characteristics as the outcome measure. The simultaneous predictor variables were childhood and current crime rates, as well as subjective fear of crime.

The first regression model was significant, and the variables together predicted approximately $15 \%$ of variance in women's preference for aggressive-formidability in an ideal male friend $(F(3,114)=7.68, p<.001)$. The only significant predictor was subjective fear of crime, which was positively correlated with ideal aggressive-formidability preference $(\beta=.41, t=4.68, p<.001)$.

The second regression model predicted approximately $10 \%$ of variance in actual aggressive-formidability of women's closest actual male friend $(F(3,114)=5.12$, $p=.002)$. Again, rather than objective crime rate measures, the subjective fear of crime emerged as the only significant, positive predictor of aggressive-formidable male friends $(\beta=.29, t=3.21, p=.001)$.

The results of Study 1 provide tentative support for the Bodyguard hypothesis in opposite-sex friend selection in young women. We predicted that neighbourhood crime rates, as well as subjective fear of crime would predict women's preference for aggressive and formidable male friends. We found that actual exposure to crime (based on current and childhood postcode information) was unrelated to male friend preference. Subjective fear of crime, however, was a significant positive predictor of aggressiveness-formidability in both actual male friends, and in the preferred characteristics of an ideal male friend. The finding that subjective fear of crime is a stronger predictor than objective crime rates mirrors previous research on romantic partner selection in women (Snyder et al. 2011; Ryder et al. 2016). The results partially replicate those of Snyder et al. (2011), and extend the Bodyguard hypothesis from the domain of mating to the realm of platonic friendships.

In order to explore the Bodyguard hypothesis further, we conducted a second study, assessing the relationship between fear of crime and both men's and women's ideal and actual same and opposite-sex friend features. As the Bodyguard hypothesis applies to male associate characteristics, we expected that aggressive-formidable traits are more important in male (rather than female) friends. However, men partially choose male coalition partners according to their strength (Benenson et al. 2009), which may be especially important in high crime environment. Thus, it is possible that men who have elevated fear of crime prefer more formidable same-sex friends, in a similar way as is predicted for women. In addition to aggressive-formidable traits, we will investigate characteristics that should be unrelated to the Bodyguard hypothesis: funniness, kindness, and intelligence. We expected no significant correlations between fear of crime and these traits.

\section{Study 2 Method}

\section{Participants and Materials}

In study 2, 228 participants ( 76 men, mean age $=23.96, S D=$ $10.55)$ entered an on-line survey, advertised via snowballing through the researchers social media, as well as on an online participation website (https://psych.hanover.edu/research/ exponnet.html). Majority of the participants were from the US $(n=180)$ and the UK $(n=33)$.

\section{Materials and Procedure}

The measure for fear of crime and the dominance trait scales were the same as in study 1 and in Snyder et al. (2011). At the end of the dominance trait scales, we added three items unrelated to aggressive-formidable traits: intelligence, kindness, and funniness. This time, participants filled in the dominance trait scale first for ideal male friends, followed by ideal female
Table 1 Descriptive statistics and Pearson's Rank correlation coefficients between ideal and actual male friend characteristics, objective current and childhood crime rates, and subjective fear of crime

\begin{tabular}{llllll}
\hline & Mean (SD) & AFA & FOC & ChCI & CuCI \\
\hline 1.Aggressive-formidable (ideal) & $2.39(1.70)$ & $.61^{* *}$ & $.40^{* *}$ & -.01 & .08 \\
2.Aggressive-formidable (actual) & $3.48(1.57)$ & - & $.31^{* *}$ & -.11 & -.10 \\
3.Fear of crime & $16.83(4.55)$ & & - &.-.12 & .03 \\
4.Childhood crime index & $5.11(1.99)$ & & & - & $.42^{* *}$ \\
5.Current crime index & $4.36(1.80)$ & & & & - \\
\hline
\end{tabular}

** $p<.01, * p<.05$, AFI Aggressive-formidable (ideal), AFA Aggressive-Formidable (actual), FOC Fear of Crime, $\mathrm{ChCI}$ Childhood crime incex, $\mathrm{CuCi}$ Current crime index 
friends. Subsequently, participants were asked to think about their best friend, and provide initials for them in order to ensure that they had a specific individual in mind. They then filled in the dominance trait scale first for their actual best male friend, followed by their actual best female friend. The final questionnaire before debrief was the measure for fear of crime.

\section{Study 2 Results}

In order to investigate whether fear of crime is related to preference for characteristics unrelated to formidability, we ran Pearson's correlations between fear of crime, and actual and ideal male and female friend intelligence, kindness, and funniness separately for both sexes. Fear of crime did not have significant correlations with any of these characteristics (all p's $>.20$; please contact the second author for full results). This shows that fear of crime is unrelated to friend characteristics that are not associated with aggressive-formidability.

We conducted a series of further Pearson's correlations in order to investigate the relationship between fear of crime and aggressive-formidability preferences in ideal and actual friends of both sexes (see Table 2). The only statistically significant correlation (albeit with a small effect size) emerged between fear of crime and preference for aggressive-formidable ideal male friends in women. To see whether fearful women have a preference for aggressive-formidable male over female partners, we tested the differences in the strength of the correlations for fear of crime and aggressive ideal male and female friends. These were not significantly different from each other (Zeigler's $\mathrm{z}=0.35, p=.70$ ). This indicates that women who are more fearful of crime have a marginal preference for aggressive-formidability traits in both male and female friends.

We also wanted to explore whether fear of crime is more strongly related to preference for aggressive-formidable friends in women than in men. The correlations between fear of crime and aggressive-formidable ideal male friends were not significantly different between the sexes (Fisher's $z=.90$, $p=.19)$. This indicates that fear of crime relates to marginal preference to aggressive-formidable male friends in both sexes, not just in women.
In order to investigate the relative contribution of sex and fear of crime in ideal and actual same and opposite-sex friend characteristics, we conducted four linear multiple regressions. In each regression, sex $(1=$ male, $2=$ female $)$ and fear of crime were entered as simultaneous predictor variables, and ideal and actual male and female friend aggressiveformidability were the outcome variables. In line with predictions from the Bodyguard hypothesis, we expected that in the models for ideal and actual male friend, sex (being female), and high fear of crime would be significant predictors. For the models for ideal and actual female friends, we did not expect any significant predictors.

The model for ideal male friend was significant $(F(4$, $222)=5.86, p=.003$ ), although the variables only predicted $4 \%$ of the choice for aggressive-formidable traits (adj $r 2=.04$ ). In line with the hypotheses, sex (being female, $\beta=.13, t=1.90, p=.05)$, and fear of crime $(\beta=.16, t=$ $2.38, p=.02$ ) emerged as significant positive predictors.

The model for ideal female friend was significant too $(F(4$, $222)=3.66, p=.03, \operatorname{adj} r 2=.02)$. Only the fear of crime was a significant predictor $(\beta=.14, t=2.11, p=.04)$. This indicates that fear of crime is an equally important predictor for aggressive-formidable female friends in both sexes. Interestingly, the models for actual male $(F(4,222)=0.93$, $p=.40)$ and female $(F(4,222)=0.98, p=.48)$ aggressiveformidability were not significant.

\section{Discussion Study 2}

Results of Study 2 provide mixed support for the Bodyguard hypothesis. When rating the characteristics of actual and ideal friends, fear or crime was unrelated to preference for traits that are not associated with the ability to provide physical protection. Previous research has found that especially for same-sex friendships, people prefer characteristics related to kindness (Lewis et al. 2011) rather than aggressiveness. This seems to be a generic preference irrespective of the levels of environmental threat, and unsurprisingly, was not associated with fear of crime.
Table 2 Pearson's Rank correlation coefficients between ideal and actual friend characteristics, and subjective fear of crime (correlations for men below diagonal)

\begin{tabular}{llllll}
\hline & AFIM & AFAM & AFIF & AFAF & FOC \\
\hline 1. Aggressive-formidable (ideal male friend) & - & $.51^{* *}$ & $.60^{* *}$ & $.21^{* *}$ & $.19^{*}$ \\
2. Aggressive-formidable (actual male friend) & $.66^{* *}$ & - & $.42^{* *}$ & $.38^{* *}$ & .10 \\
3. Aggressive-formidable (ideal female friend) & .12 & $.55^{* *}$ & - & $.56^{* *}$ & .15 \\
4. Aggressive-formidable (actual female friend) & .07 & $.56^{* *}$ & & - & .01 \\
5. Fear of crime & .07 & .07 & .12 & .07 & - \\
\hline
\end{tabular}

** $p<.01,{ }^{*} p<.05$, AFIM Aggressive-formidable (ideal male friend), AFAM Aggressive-formidable (actual male friend), AFIF Aggressive-formidable (ideal female friend), AFAF Aggressive-formidable (actual female friend, FOC Fear of crime 
For the preference for ideal friend characteristics, fear of crime had a significant positive correlation with women's ratings of male aggressive-formidable traits. On the surface, this appears to support the Bodyguard hypothesis further, as no significant correlations were found for men's fear of crime, and formidability in friends. However, sex did not moderate this relationship, as the correlations were not significantly different between men and women. This implies that fearfulness correlates with a marginal preference for formidable friends in both sexes.

In addition, women who had higher levels of fear did not prefer formidable male friends more than they preferred formidable female friends. Although the correlation between women's fear of crime and formidability preference in ideal female friends was not significant, it was in the positive direction. It is possible that women who fear crime (and hence, would benefit from protection from their environment) have a weak preference for both male and female partners who are aggressive-formidable. In this sense, the Bodyguard hypothesis is something that could potentially be applied to desired same-sex, as well as opposite-sex friend characteristics in women. Future research should focus on investigating how dangerous environments influence the characteristics of women's ideal male and female friends.

Interestingly, in this sample, aggressive-formidable characteristics of the actual friend were not related to fear of crime. In reality, the actual opposite-sex friends may be different to the mental image about opposite-sex friends (Bleske-Rechek et al. 2016). Discrepancies between ideal and actual friend characteristics are not uncommon (Demir and Orthel 2011), and our study shows the discrepancies could extend to aggressiveformidable traits too. In the context of our study, it is possible that the ideal friend is more closely matched with predictions drawn from the Bodyguard hypothesis than the actual friend.

\section{General Discussion}

Our two studies investigated the Bodyguard hypothesis in relation to a previously under-investigated topic, women's choice for opposite-sex friend characteristics. In two studies, we found that (i) subjective, rather than objective crime in the environment related to women's preference for male friends who are able to provide physical protection, (ii) in both sexes, fear of crime was unrelated to friend characteristics that are irrelevant in physical protection, (iii) both sexes had a weak preference for ideal male and female friends that are aggressive and formidable, and (iv) ideal aggressive-formidability may be in line with the Bodyguard hypothesis more closely than actual aggressive-formidability in best friends.

Previous research has found that exposure to crime in childhood influences current perceptions of crime (Sherman et al. 2016), as well as a preference for aggressive-formidable long-term partners (Snyder et al. 2011). In our first study, objective crime rates in childhood were unrelated to male friend preference. However, the crime index in our study included all types of crime, including violent crime, property crime, and so on. In the study of Snyder et al. (2011), preference for aggressive-formidable men was more prominent for those who lived in areas with more recorded violent crimes. It is possible that the inability to separate crime types in our study explains the non-significant results. Future studies should take the crime types into consideration.

The results presented here point at the importance of subjective perceptions of the environment as the most important determinant of evolutionarily sensible choices when selecting friends. Although danger in childhood environment is related to current perception of risk (Sherman et al. 2016), the current, subjective fear of crime is more crucial. Women who have higher fear of crime (irrespective of their actual environment) have been found to prefer aggressive-formidable male partners (Ryder et al. 2016). We suggest that this self-assessed vulnerability also relates to a preference for non-romantic social partners who can offer protection from violence. Interestingly, the correlations for fear of crime and ideal aggressive-formidable friends did not differ significantly between male and female participants. Men may choose their coalition partners partially according to their strength (Benenson et al. 2009), and strength in the form of aggressive-formidable traits could have an increased importance in dangerous environments. In addition, a previous study found that men's mate choice varies in different environments (i.e., femininity was preferred less in poorer health conditions; Marcinkowska et al. 2014). It is clear that suboptimal socio-ecological circumstances influence men's preferences for their non-romantic friend characteristics too.

Our study should be considered as a preliminary investigation onto the Bodyguard hypothesis in friendship selection. Future studies could look at real friendships to gain more objective measures of the formidability of friends. In addition, it would be interesting to study the Environmental security hypothesis (Reeve et al. 2019) in relation to preference for friend characteristics. Perhaps women who are faced with an environmental risk unrelated to crime also have a preference for male friends who can provide physical protection. Finally, the priming methodology has been successfully applied in previous studies on mate selection (e.g., Sacco et al. 2015; Snyder et al. 2011), and could easily be replicated in the context of friendships. Perhaps priming participants with high crime environments would shift their friend preferences towards higher formidability. All of these ideas would bring more light to an under-investigated area of research.

In conclusion, women's opposite-sex friends could serve an important function of providing protection. More specifically, both men and women who feel vulnerable to crime may have biases towards preferring aggressive and formidable 
friends. The results of these studies provide some tentative evidence for the Bodyguard hypothesis in friend selection, which should be investigated further in future studies using more diverse methodologies and samples.

\section{Compliance with Ethical Standards}

Statement of Conflict of Interest On behalf of all authors, the corresponding author states that there is no conflict of interest.

Ethical Statement (Including the Name of the Approval Board) All procedures performed in studies involving human participants were in accordance with the ethical standards of the institutional and/or national research committee (Psychology ethics committee, reference 4005) and with the 1964 Helsinki declaration and its later amendments or comparable ethical standards."

Informed Consent "Informed consent was obtained from all individual participants included in the study."

Open Access This article is licensed under a Creative Commons Attribution 4.0 International License, which permits use, sharing, adaptation, distribution and reproduction in any medium or format, as long as you give appropriate credit to the original author(s) and the source, provide a link to the Creative Commons licence, and indicate if changes were made. The images or other third party material in this article are included in the article's Creative Commons licence, unless indicated otherwise in a credit line to the material. If material is not included in the article's Creative Commons licence and your intended use is not permitted by statutory regulation or exceeds the permitted use, you will need to obtain permission directly from the copyright holder. To view a copy of this licence, visit http://creativecommons.org/licenses/by/4.0/.

\section{References}

Benenson, J. F., Markovits, H., Emery Thompson, M., \& Wrangham, R. W. (2009). Strength determines coalitional strategies in humans. Proceedings of the Royal Society B: Biological Sciences, 276, 2589-2595.

Bleske-Rechek, A. L., \& Buss, D. M. (2001). Opposite-sex friendship: Sex differences and similarities in initiation, selection, and dissolution. Personality and Social Psychology Bulletin, 27, 1310-1323.

Bleske-Rechek, A., Somers, E., Micke, C., Erickson, L., Matteson, L., Stocco, C., Schumacher, B., \& Ritchie, L. (2012). Benefit or burden? Attraction in cross-sex friendship. Journal of Social and Personal Relationships, 29, 569-596.

Bleske-Rechek, A., Joseph, W. E., Williquette, H., \& Donovan, B. (2016). Sex differences in young adults' attraction to opposite-sex friends: Natural sampling versus mental concepts. Evolutionary Psychological Science, 2, 214-219.

Borras-Guevara, M. L., Batres, C., \& Perrett, D. I. (2017). Aggressor or protector? Experiences and perceptions of violence predict preferences for masculinity. Evolution and Human Behavior, 38, 481-489.

Buss, D. M., \& Schmitt, D. P. (1993). Sexual strategies theory: An evolutionary perspective on human mating. Psychological Review, 100, 204-232.

Demir, M., \& Orthel, H. (2011). Friendship, real-ideal discrepancies, and well-being: Gender differences in college students. The Journal of Psychology, 145, 173-193.
English indices of deprivation (2015). Retrieved April 30, 2019, from http://imd-by-geo.opendatacommunities.org/area.

Goffe, A. S., Zinner, D., \& Fischer, J. (2016). Sex and friendship in a multilevel society: Behavioural patterns and associations between female and male Guinea baboons. Behavioral Ecology and Sociobiology, 70, 323-336.

Lewis, D. M., Conroy-Beam, D., Al-Shawaf, L., Raja, A., DeKay, T., \& Buss, D. M. (2011). Friends with benefits: The evolved psychology of same-and opposite-sex friendship. Evolutionary Psychology, 9(4), 147470491100900407.

Marcinkowska, U. M., Kozlov, M. V., Cai, H., Contreras-Garduño, J., Dixson, B. J., Oana, G. A., et al. (2014). Cross-cultural variation in men's preference for sexual dimorphism in women's faces. Biology Letters, 10(4), 20130850.

Monsour, M. (2002). Women and men as friends: Relationships across the life span in the $21^{\text {st }}$ century. Mahwah: Lawrence Erlbaum.

Office for National Statistics (2017). Public perceptions of crime in England and Wales: year ending March 2016. Retrieved April 10, 2019 , from ht tps://ww w.ons.gov.uk/ peoplepopulationandcommunity/crimeandjustice/articles/ publicperceptionsofcrimeinenglandandwales/ yearendingmarch2016\#what-other-sources-of-information-areavailable-on-perceptions-of-crime.

Poore, J. C., Gable, S. G., \& Haselton, M. G. (2006). The content and structure of mate-value. Poster presented at the 7th Annual Meeting of the Society for Personality and Social Psychology. Palm Springs, California.

Reeve, S. D., Kelly, K. M., \& Welling, L. L. (2016). Transitory environmental threat alters sexually dimorphic mate preferences and sexual strategy. Evolutionary Psychological Science, 2(2), 101-113.

Reeve, S. D., Mogilski, J. K., \& Welling, L. L. (2019). Environmental safety threat alters mate choice processes in humans: Further evidence for the environmental security hypothesis. Evolutionary Psychological Science, 5, 186-198.

Ryder, H., Maltby, J., Rai, L., Jones, P., \& Flowe, H. D. (2016). Women's fear of crime and preference for formidable mates: How specific are the underlying psychological mechanisms? Evolution and Human Behavior, 37, 293-302.

Sacco, D., Lustgraaf, C., Brown, M., \& Young, S. (2015). Activation of self-protection threat increaes women's preferences for dominace in male faces. Human Ethology Bulletin, 30(4), 23-31.

Sherman, A. K., Minich, S. H., Langen, T. A., Skufca, J., \& Wilke, A. (2016). Are college students' assessments of threat shaped by the dangers of their childhood environment? Journal of Interpersonal Violence, 31, 1-20.

Snyder, J. K., Fessler, D. M., Tiokhin, L., Frederick, D. A., Lee, S. W., \& Navarrete, C. D. (2011). Trade-offs in a dangerous world: Women's fear of crime predicts preferences for aggressive and formidable mates. Evolution and Human Behavior, 32, 127-137.

Sprecher, S., \& Regan, P. C. (2002). Liking some things (in some people) more than others: Partner preferences in romantic relationships and friendships. Journal of Social and Personal Relationships, 19, 463-481.

Tunstall, R. (2016). Are neighbourhoods dynamic or are they slothful? The limited prevalence and extent of change in neighbourhood socio-economic status, and its implications for regeneration policy. Urban Geography, 37, 769-784.

Wilson, M., \& Mesnick, S. L. (1997). An empirical test of the bodyguard hypothesis. In Feminism and evolutionary biology (pp. 505-511). Boston: Springer. https://doi.org/10.1007/978-1-4615-5985-6_21.

Zhao, J. S., Lawton, B., \& Longmire, D. (2015). An examination of the micro-level crime-fear of crime link. Crime \& Delinquency, 61, 19-44.

Publisher's Note Springer Nature remains neutral with regard to jurisdictional claims in published maps and institutional affiliations. 